Guadalupe Valencia García

\section{Entre cronos y kairós. Las formas del tiempo histórico}

(Barcelona, Editorial Anthropos, 2007)

\section{Prolegómenos a una sociología del tiempo}

Precedido por un prólogo de Josetxo Beriain, este bello libro de Guadalupe Valencia permite al público español ponerse al tanto de los desarrollos de la sociología del tiempo en México. La autora es investigadora del Centro de Investigaciones Interdisciplinarias en Ciencias y Humanidades de la UNAM, un centro de investigación pequeño, pero gigantesco por su productividad, que fundara e impulsara Pablo González Casanovas como lugar de encuentro para científicos y humanistas interesados en debatir y esclarecer los conceptos fundamentales con los que pensamos el mundo -o con los que éste nos piensa-. A lo largo de las últimas décadas, el Centro ha organizado encuentros de los que han surgido múltiples libros. Entre ellos destacan los organizados por Guadalupe Valencia sobre el tiempo (seminarios multidisciplinares celebrados en 2003 y 2006), en los que un amplio espectro de pensadores (artistas, escritores, científicos sociales, científicos naturales, especialistas en humanidades, etc.) han puesto en común sus saberes para ver si se entreveraban y alimentaban mutuamente. Como participante en esas reuniones, este reseñador confiesa que fueron muy productivas y que la razón de su éxito hay que otorgárselo a quien, tras una lenta maduración, se ha decidido por fin a publicar el libro que ahora comento.
Entre cronos y kairós es un prolegómeno a la sociología del tiempo. Como todo prolegómeno, es el intento de fijar los fundamentos de un saber todavía no construido, pero en construcción. La autora da dos pistas fundamentales para que el lector comprenda la dirección de su labor de fundamentación: una de ellas tiene que ver con una teoría general del tiempo; la otra, con el proyecto de una sociología plenamente temporalizada.

En efecto, Valencia asegura, con toda la razón del mundo, que la aproximación sociológica al estudio del tiempo ha de empaparse de la tradición multisecular de estudios que ha debatido incansablemente ese intrincado objeto de estudio. No debemos dar por sentado y resuelto el concepto de tiempo, viene a decir, sino reconstruir la tradición de los debates que sobre él se han entretejido para intentar disipar sus oscuridades. En definitiva, una sociología del tiempo ha de partir de una teoría del tiempo que recoja el legado de la tradición, sin arriesgarse a dar por sobreentendido y aproblemático ese tiempo en el que acabaría quedando enredada. Enfrentando este reto, Valencia propone una cierta disolución dialéctica de la tradición, reconduciendo sus tercos dualismos a una concepción bidimensional del tiempo cuyos polos encuentran mediación para hacer fácil el tránsito entre uno y otro. De ahí el mismo título del libro, entre cronos y kairós, pues, recogiendo la vieja terminología griega (que en sociología ya había sido hábilmente explotada por el británico Eliot Jaques en La Forma del Tiempo), Valencia propone que el tiempo no se puede reducir ni al concepto más propiamente aristotélico (pero newtoniano también) de un cronos-entorno que fluye por sí mismo y en el 
que se sitúan (o son situables) los acontecimientos, ni al concepto más propiamente paulino-agustiniano de un kairós que, dando cuenta de la ocasión u oportunidad, hace también referencia a la vivencia o conciencia temporal de una criatura que apetece la eternidad pero está desgarrada en un presente en el que recuerda y espera. A estas dos experiencias del tiempo las denomina Valencia su bidimensionalidad (aunque también en ocasiones su dualidad, que no dualismo), dando a entender por tal la co-presencia de dos caras o aspectos del tiempo irreductibles entre sí e ineliminables. Aristóteles y Agustín de Hipona dándose la mano sin ocultar su tensión: tal me parece la propuesta que se argumenta en la primera parte del libro.

La otra dirección que antes anunciaba en esta labor de fundamentación tiene que ver con lo que Valencia privilegia en la doble tarea que ha de enfrentar una sociología del tiempo. Pues, como es obvio, por una empresa tal se puede entender tanto la que procede a una socialización o sociologización del tiempo (el tiempo leído en clave de estructuras y procesos sociales) como la que atiende a una temporalización de lo social (lo social y la sociología misma leídos en clave de tiempo y temporalidad). Son, obviamente, las dos tareas o cometidos posibles de una sociología del tiempo. Valencia piensa que la segunda es más urgente y que, por lo tanto, la fundamentación ha de proceder en el camino de apuntar a las fuentes disponibles para una temporalización plena de la sociología. Es obvio lo que así se significa: una sociología temporalizada sería una en que fuera muy explícito el reconocimiento del carácter temporal de su objeto de observación y, consecuentemente, del instrumental metodológico y analítico apto para abordarlo y desentrañarlo. ¿Dónde conseguir las metáforas, intuiciones, ideas o conceptos temporales para hacerlo? La propuesta de Valencia es que atendiendo doblemente a los desarrollos actuales de las ciencias naturales y formales (esas hermanas mayores de tradición más bien eleática, afortunadamente superada) y a una nueva aproximación sociológica a la historia. De ambas fuentes se obtienen en abundancia nociones temporales especialmente útiles para una sociología renovada.

Los desarrollos actuales (o ya no tanto, pues las propuestas de Prigogine en las que Valencia se inspira llevan ya unas cuantas décadas en el mercado de las ideas) de la física, la química o la biología han puesto en el debate académico nuevas ideas sobre la complejidad, la incertidumbre, los sistemas dinámicos, la irreversibilidad, la pluralidad, la contingencia, los horizontes de mundos posibles, etc., que no hacen sino poner a trabajar nuevas maneras de concebir el tiempo. Esas nuevas ideas trascienden el saber que era hegemónico hasta hace poco, que todo lo reducía al entrechocar de objetos simples en procesos lineales. La propuesta de Valencia es que los sociólogos han de abrirse a esos riquísimos experimentos conceptuales que, para poder dar cuenta de la complejidad irreductible de la materia, exploran caras nuevas del tiempo.

La otra fuente para una renovada temporalización de la sociología ha de venir de la mano de una nueva aproximación a la historia. Ciertamente, se trata de atender a lo que ha venido llamándose la sociología histórica. Pero, más allá de esto, lo que propone Valencia es que se 
afirme una nueva sensibilidad sociológica para la historicidad, entendida ésta en el doble sentido de aquello que resulta del devenir y está ya hecho y de aquello que está todavía abierto a su conformación, ya sea porque está haciéndose, ya sea porque todavía se ha de hacer. Una sociología que atienda a la historicidad en este sentido ha de abrirse a una activa incorporación del tiempo en sus pliegues más sutiles y reveladores: las iteraciones temporales, los juegos de la memoria y el olvido, las relaciones entre el espacio de la experiencia y el horizonte de la expectativa, la utopía, el novum blochiano, etc.

Evidentemente, el libro que comento no puede reducirse a la argumentación de estas dos líneas de investigación que he querido destacar. Muchos otros son los aspectos del tiempo a los que atiende su curiosidad. Al hilo de su voracidad temporal se va comentando aquí y allá una riquísima literatura que une a los pensadores clásicos con los pensadores más actuales, sin atender a las cansinas barreras disciplinares que impiden el diálogo productivo entre los distintos pensadores (filósofos, biólogos, historiadores, físicos, sociólogos, etc.) del tiempo. Esto le proporciona una riqueza conceptual envidiable, poco usual en la literatura sociológica del tiempo. Con todo, hay veces en que esa riqueza, y sobre todo el anhelo de incorporar ecuménicamente elementos e ideas de orígenes muy dispares, juegan en contra de la claridad y el rigor exigibles a un trabajo tan ambicioso y valiente. Así -y por destacar algo que se insinúa y me parece atractivo, pero que no está suficientemente desarrollado y resulta más bien oscuro-, esa incursión que se realiza en las páginas 79 a 81 sobre un posible espacio- tiempo social hexadimensional, cuyos fundamentos y perfiles no quedan claros.

En cualquier caso, como la obra se sabe un prolegómeno, se presenta como una labor de fundamentación de algo que se habrá de realizar en el futuro, una vez acabada esta labor preliminar. Ese algo es una sociología del tiempo que aborde el estudio de la temporalidad de los fenómenos sociales. En las páginas del libro hay veces en que se aboceta lo que esa tarea podría dar de sí. Tal es el caso cuando se hacen puntuales aproximaciones al análisis de las estructuras temporales de los movimientos sociales contemporáneos -especialmente el zapatista, que tan explícitos ha hecho en sus declaraciones políticas los distintos juegos del tiempo-. Confiemos, pues, en el/lo porvenir, pues bueno sería que lo que ahora se aboceta en el futuro se desarrollara plenamente y este intento de fundamentación de una sociología temporalizada mostrara sus virtudes analíticas abordando el estudio de casos.

Ramón RAMOS TORRE

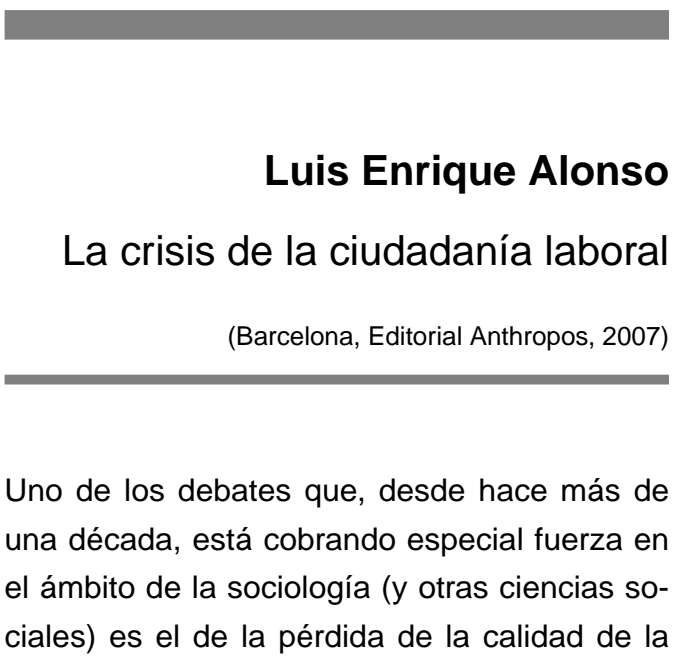

